\title{
Reduction of exogenous ferric iron by a surface-associated ferric reductase of Listeria spp.
}

\author{
Harry G. Deneer, ${ }^{1,2}$ Vanessa Healey $^{2}$ and Irene Boychuk ${ }^{1}$
}

Author for correspondence: Harry G. Deneer. Tel: +1 306655 1782. Fax: +1 3069664311.

Department of

Microbiology, University of Saskatchewan, ${ }^{1}$ and

Division of Clinical

Microbiology, Royal

University Hospital, 2

Saskatoon, Saskatchewan,

Canada, S7N 5E5

\begin{abstract}
The reduction of exogenous ferric iron by Listeria monocytogenes, a Grampositive food-borne pathogen, was investigated. Using an assay incorporating the ferrous iron chelator ferrozine, we showed that intact cells of $L$. monocytogenes, when exposed to ferric iron, were able to rapidly reduce and solubilize the iron to the ferrous form. Reduction occurred only after direct contact between the bacteria and the iron source. A number of different ferric iron chelates, including transferrin and lactoferrin-bound iron, haemoglobin, ferritin, and iron complexed to siderophores, could be reduced. The ferric reductase activity was expressed by both reference strains and clinical isolates of $L$. monocytogenes and by all other species of Listeria, although significant quantitative differences were observed. In L. monocytogenes, the expression of ferric reductase was not affected by the growth phase of the bacteria nor by the presence or absence of iron in the growth medium. However, expression was greatly reduced in bacteria grown anaerobically and when cultured in media of reduced pH. In addition, bacteria grown at a cold temperature displayed greater ferric reductase activity than cells grown at higher temperatures. A surface-associated ferric reductase system may be one component of a general iron scavenging mechanism which can be used by Listeria growing in a variety of environments.
\end{abstract}

Keywords: Listeria monocytogenes, ferric iron reduction, surface-associated activity, ferritin, temperature-regulated expression

\section{INTRODUCTION}

Listeria monocytogenes is an opportunistic Gram-positive bacterium responsible for meningoencephalitis, spontaneous abortions, perinatal infections and septicaemia in humans (Kluge, 1990; Farber \& Peterkin, 1991). Being a food-borne pathogen, it is readily able to grow at refrigeration temperatures in a variety of food and dairy products. It is also widely distributed in the environment, having been isolated from water, soil, decaying vegetation, animal silage, and raw and treated sewage. Finally, because it is a facultative intracellular pathogen, it is able to replicate within the cytoplasm of macrophages, hepatocytes, fibroblasts and other cell types.

While much has recently been learned about the ability of $L$. monocytogenes to escape into the cytoplasm of host cells and initiate rapid cell to cell spread (Portnoy et al., 1992),

Abbreviation: SGM, standard growth medium little attention has been devoted to the actual metabolic processes driving both intracellular and extracellular growth. Iron, for example, is required by Listeria in relatively large amounts to support growth during experimental infections (Sword, 1966). However, the mechanism by which Listeria acquires iron and the potential sources of this iron have remained poorly defined. This is particularly significant given the diverse environmental distribution of the organism and the fact that iron can be sequestered in many forms depending on the environment - ranging from insoluble ferric $\left(\mathrm{Fe}^{3+}\right)$ hydroxides and oxyhydroxides in aerobic environments, to ferric transferrin in serum and bound to ferritin and haem compounds intracellularly (Neilands, 1981; Crichton \& Ward, 1992). Many micro-organisms secrete siderophores which chelate ferric iron and utilize periplasmic or cytoplasmic ferrisiderophore reductases to release the iron in the ferrous $\left(\mathrm{Fe}^{2+}\right)$ form and make it available for cellular metabolism. Siderophores have not been identified in Listeria, although Cowart \& Foster 
(1985) detected a low molecular mass, soluble 'reductant' which was capable of reducing and releasing iron from transferrin. This reductant has not yet been fully characterized (Cowart et al., 1988) and its role in iron acquisition is unknown. More recent studies have demonstrated that L. monocytogenes could bind ferrous iron and ferric citrate, but not ferric ferroxamine, ferric EDTA or unligated $\mathrm{FeCl}_{3}$, to the cell surface (Adams et al., 1990). The current model for iron acquisition by Listeria, as delineated by Adams et al. (1990), proposes that at least two mechanisms are operative; one involves the direct binding of ferric citrate to the cell, while the other uses a cell surface receptor specific for ferrous iron followed by transport of the reduced iron into the cell. How this ferrous iron is generated is unknown but would possibly involve the extracellular reductant secreted by the bacterium.

We have sought to clarify the mechanistic details of iron acquisition by Listeria, and have previously described a technique by which the reduction of ferric iron can be observed in colonies of Listeria growing on agar surfaces (Deneer \& Boychuk, 1993). We report here that whole cells of $L$. monocytogenes can efficiently reduce many forms of ferric iron and that reduction only occurs after direct contact between the bacteria and the iron source. In addition, the reducing activity is strongly influenced by culture conditions such as growth temperature and aerobiosis and is seen in all species of Listeria, albeit to varying degrees.

\section{METHODS}

Bacterial strains. Most of the strains of $L$. monocytogenes used in this study have been described previously (Deneer \& Boychuk, 1993; Vasconcelos \& Deneer, 1994) and were obtained either from the American Type Culture Collection (Rockville, MD, USA) or as clinical isolates from the Royal University Hospital, Saskatoon, Sk, Canada. In addition, L. monocytogenes 615776 was a blood isolate from a patient with myelofibrosis and 223566 was isolated from the spinal fluid of a patient with Hodgkin's disease. Representative strains of other Listeria species were as described previously (Deneer \& Boychuk, 1993), while Escherichia coli $\mathrm{O} 157$ and Enterococcus faecalis were from our laboratory collection.

Chemicals. All chemicals were obtained from Sigma with the exception of the following: ferric ammonium citrate $(16.5-18.5 \%, w / w, F e)$ from Mallinckrodt, proteinase $K$ and trypsin from Boehringer Mannheim. Human transferrin and lactoferrin were deferrated and brought up to $50 \%$ iron saturation with ferrous chloride (Simonson et al., 1982). The ferric chelate of 2,3-dihydroxybenzoic acid was prepared with $\mathrm{FeCl}_{3}$ at a siderophore/iron ratio of 3:1 (Gaines et al., 1981) while iron was complexed to desferriferoxamine mesylate (Desferal) as described by Moody \& Dailey (1984). Prior to use, the haemoglobin and the holo-iron form of ferritin (Type I from horse spleen) were dialysed against water containing $1 \%(\mathrm{w} / \mathrm{v})$ chelex-100 (Bio-Rad) to remove loosely bound iron.

Media and growth conditions. 'Tryptic-soy broth with $0.1 \%$ glucose (BRL) and Luria broth (Difco) were prepared and autoclaved separately, then mixed together in a $1: 1$ ratio and used as the standard growth medium (SGM). When required, liquid media were treated with conalbumin A (Gutteridge,
1987), which reduced the level of iron to about $1 \cdot 5-2 \cdot 0 \mu \mathrm{M}$ as determined by the bleomycin assay (Gutteridge, 1987). Aerobic growth was achieved by placing $20-50 \mathrm{ml}$ SGM in a $250 \mathrm{ml}$ Erlenmeyer flask and shaking at 200 r.p.m. on a rotary shaking platform. For static growth, $20 \mathrm{ml} \mathrm{SGM}$ was placed into a $50 \mathrm{ml}$ Falcon tube and incubated without shaking. For anaerobic growth, cells in SGM were placed in a Gas-Pak Anaerobic Jar (Becton-Dickinson). Bacteria were usually grown for $18 \mathrm{~h}$ before they were assayed for ferric iron-reducing activity. However, for experiments where the growth temperature was reduced, it was necessary to incubate the cultures for $48-72 \mathrm{~h}$ to achieve sufficiently high cell densities.

Standard whole-cell ferric reductase assay. The reduction of ferric to ferrous iron was measured by trapping the $\mathrm{Fe}^{2+}$ as a coloured complex with ferrozine [3-(2-pyridyl)-5,6-bis-(4phenylsulfonic acid)-1,2,4-triazine] as first described by Dailey \& Lascelles (1977) and is modified from a procedure developed for yeast cells by Dancis et al. (1990). Prior to assaying, the $\mathrm{OD}_{600}$ of the cell culture was measured. Cells were then harvested by centrifugation, washed once with PBS, then resuspended in conalbumin-treated tryptic-soy broth to the same volume as originally harvested. Seven millilitres of cells were placed into $15 \mathrm{ml} \mathrm{Falcon}$ tubes and the following reagents were added: $\mathrm{MgCl}_{2}(10 \mathrm{mM})$, NADH $(50 \mu \mathrm{M})$, FMN $(3 \mu \mathrm{M})$, ferrozine $(2 \mathrm{mM})$, ferric ammonium citrate $\left(100 \mu \mathrm{g} \mathrm{ml}^{-1}\right.$ final concentration). Immediately after addition of the iron, the contents of the tube were mixed, the caps removed, and the tubes placed in a stationary $37^{\circ} \mathrm{C}$ water bath. At 5 min intervals, $1 \mathrm{ml}$ aliquots of the reactants were removed and centrifuged at $14000 \mathrm{~g}$ for $1 \mathrm{~min}$ to pellet the cells. The supernatant was carefully removed and the absorbance of the $\mathrm{Fe}^{2+}$-ferrozine complex was measured at $562 \mathrm{~nm}$. The spectrophotometer was blanked at each time point using a control reaction consisting of all reagents, except for bacterial cells, incubated in parallel with the test assay. The amount of $\mathrm{Fe}^{2+}$-ferrozine produced was calculated using a molar extinction coefficient of 27900 (Stookey, 1970). Specific activity of the ferric reductase was expressed as $\mu \mathrm{mol} \mathrm{Fe}^{2+}$-ferrozine formed per minute per 1 optical density unit of cells ( $\mu \mathrm{mol} \mathrm{Fe}{ }^{2+}$-ferrozine min $^{-1} \mathrm{ODU}^{-1}$ ) and was calculated from the linear portion of a timed assay (e.g. Fig. 1). For some experiments, the ferric ammonium citrate was replaced by other sources of iron.

Equilibrium dialysis assay. Assays in which the iron source was separated from Listeria cells by a dialysis membrane were modified from that described by Yang et al. (1993). A small square of dialysis membrane (Spectrapor $25000 \mathrm{Da}$ cutoff, Spectrum) was positioned over the end of a hollow glass tube $(8 \mathrm{~cm} \times 1 \mathrm{~cm})$ and held in place with a rubber collar. Into this tube was placed $1.5 \mathrm{ml}$ of a reaction mix consisting of trypticsoy medium, $\mathrm{MgCl}_{2}, \mathrm{NADH}, \mathrm{FMN}$ and ferrozine at the same concentrations as used in the standard ferric reductase assay. In addition, ferritin at a final concentration of $1 \mathrm{mg} \mathrm{m}^{-1}$ was placed into the tube as an iron source. The entire tube plus reactants was then placed into a $50 \mathrm{ml}$ Falcon tube containing $4 \mathrm{ml}$ of a mixture of washed bacterial cells plus all the reactants described above with the exception of ferritin. Therefore, the iron source inside the tube was physically separated from the bacterial cells by a dialysis membrane while all other components were equal on both sides of the membrane. This assembly was gently shaken for $45 \mathrm{~min}$ at $37^{\circ} \mathrm{C}$, at which time the amount of $\mathrm{Fe}^{2+}$-ferrozine complex formed on each side of the membrane was determined by measuring $A_{562}$. In a control reaction, all components were present without separation by a membrane (bacterial cells and ferritin in direct contact).

Treatment of cells with proteolytic agents. Cells were 
harvested as described above and resuspended in TM buffer (10 mM Tris/HCl, $\mathrm{pH} \mathrm{7.5;1} \mathrm{mM} \mathrm{MgCl}_{2}$ ). To this was added either proteinase $\mathrm{K}\left(0.5 \mathrm{mg} \mathrm{ml}^{-1}\right.$ final concentration) or trypsin $\left(1 \mathrm{mg} \mathrm{ml} l^{-1}\right)$ and the suspension incubated at $37^{\circ} \mathrm{C}$ for $45 \mathrm{~min}$. The cells were then washed twice with PBS, resuspended in tryptic-soy medium, and assayed for ferric reductase activity as before. Treatment of cells with SDS was as described by Kocks et al. (1992). A washed cell pellet in TM buffer was incubated with $1 \%(\mathrm{v} / \mathrm{v})$ SDS for $5 \mathrm{~min}$ with gentle rocking, then washed twice with PBS prior to performing a whole-cell ferric reductase assay.

Proteolytic degradation of iron-protein compounds. Bacteria were grown in SGM at room temperature for $18 \mathrm{~h}$, then harvested and resuspended in fresh tryptic-soy broth to one-half of the original volume. To this was added either ferritin, transferrin or lactoferrin to a final concentration of $1 \mathrm{mg} \mathrm{m}^{-1}$. The mixture was placed at $37^{\circ} \mathrm{C}$ and aliquots were withdrawn at 30 min intervals. After removal of bacteria by centrifugation, a sample of the supernatant containing $20 \mu \mathrm{g}$ total protein was electrophoresed under non-denaturing conditions on a native polyacrylamide gel. Proteins were visualized by staining with Coomassie Brilliant Blue R-250.

\section{RESULTS}

\section{Reduction of ferric iron by $L$. monocytogenes}

We had previously shown that ferrozine, a colorimetric chelator of ferrous iron, could be used to follow the extracellular reduction of ferric iron by colonies of Listeria

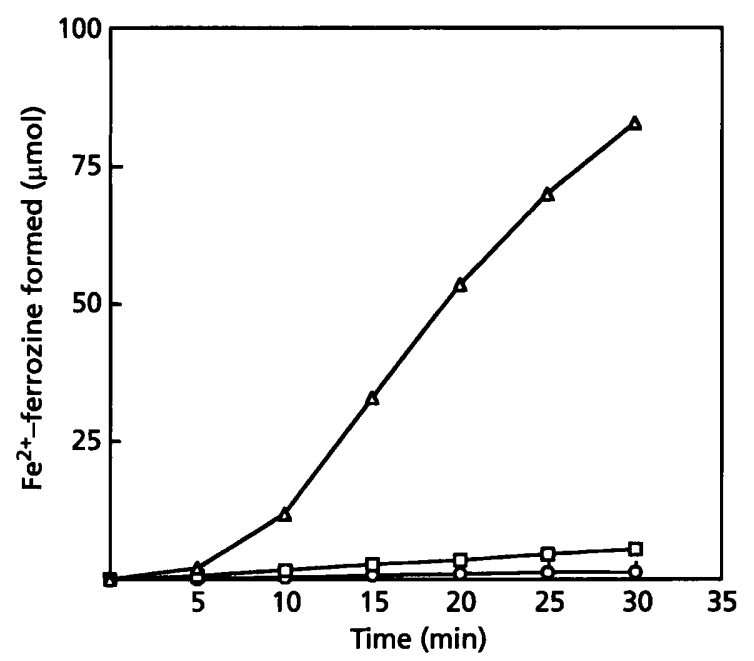

Fig. 1. Reduction of ferric iron by $L$. monocytogenes ATCC 35152. $\triangle$, A washed cell suspension of $L$. monocytogenes was incubated with ferric ammonium citrate and ferrozine as described in Methods; at 5 min intervals an aliquot was taken, the cells removed and the amount of $\mathrm{Fe}^{2+}$-ferrozine formed in the supernatant was determined from the $O D_{562}$ value. $O$, Control reaction in which all components were incubated as above but bacterial cells were not included in the assay. $\square$, Ferric ammonium citrate and ferrozine were incubated with spent cell-free culture supernatant from an overnight culture of $L$. monocytogenes and assayed spectrophotometrically for $\mathrm{Fe}^{2+}$-ferrozine. The data shown is representative of two separate experiments.
Table 1. Effect of reaction components on $\mathrm{Fe}^{3+}$ reduction by $L$. monocytogenes 35152

\begin{tabular}{|lc|}
\hline Reaction composition* & $\begin{array}{c}\text { Specific activity } \\
\left(\boldsymbol{\mu m o l} \mathbf{F e}^{2+} \text {-ferrozine }\right. \\
\left.\mathbf{m i n}^{-1} \mathbf{O D U}^{-1}\right) \dagger\end{array}$ \\
\hline Complete & $3.78(100 \%)$ \\
- FMN & $2.28(60 \%)$ \\
- $\mathrm{Mg}^{2+}$ & $2.55(67 \%)$ \\
- NADH & $3.21(85 \%)$ \\
- FMN, -NADH, $-\mathrm{Mg}^{2+}$ & $1.93(51 \%)$ \\
- NADH, +NADPH & $3.15(83 \%)$ \\
- Ferric iron & $0(0)$ \\
\hline
\end{tabular}

*Indicates a complete assay as described in the Methods or an assay in which the indicated component has been omitted. The iron source was ferric ammonium citrate. Bacteria were grown aerobically at $37^{\circ} \mathrm{C}$ before being used in an assay.

† Numbers in brackets indicate the specific activity as a percentage of that obtained with a complete reaction. Data shown is representative of three separate assays.

spp. (Deneer \& Boychuk, 1993). To obtain a more quantitative indication of iron reduction, we incubated a washed whole-cell suspension of $L$. monocytogenes ATCC 35152 with ferric citrate and ferrozine and followed the accumulation, over time, of the magenta-coloured $\mathrm{Fe}^{2+}$ ferrozine complex in the supernatant. As shown in Fig. 1, reduction of $\mathrm{Fe}^{3+}$ was evident almost immediately and achieved a maximum rate after $15-20 \mathrm{~min}$. In contrast, virtually no spontaneous reduction of $\mathrm{Fe}^{3+}$ occurred in the absence of bacteria (Fig. 1) or if heat-killed cells $\left(90^{\circ} \mathrm{C}, 20 \mathrm{~min}\right.$ ) were used in the assay (not shown). To see if cell-free culture supernatants possessed an $\mathrm{Fe}^{3+}$-reducing activity, as suggested by Cowart \& Foster (1985), we added ferric citrate-ferrozine reagents to the spent medium from an overnight culture of $L$. monocytogenes and measured the accumulation of $\mathrm{Fe}^{2+}$-ferrozine. Very little reduction of ferric iron occurred over a $30 \mathrm{~min}$ incubation period (Fig. 1). Although the growth media for this experiment was a mixture of tryptic soy and Luria broths, similar results (not shown) were obtained when Listeria were grown in other nutrient media, including tryptic soy broth, brain heart infusion (BHI) broth and $\mathrm{BHI}$ treated with $\mathrm{CaCl}_{2}$ (Cowart \& Foster, 1985).

Our standard $\mathrm{Fe}^{3+}$ reduction assay included NADH, FMN and magnesium, components reportedly required for the activity of the secreted 'reductant' found in $L$. monocytogenes culture supernatants (Cowart \& Foster, 1985). The omission of all three components from the whole-cell ferric reduction assay resulted in a decrease in $\mathrm{Fe}^{3+}$-reducing activity of about $50 \%$, whereas the absence of any individual component gave a decline of 15-40\% (Table 1). We noted that, while the absence of NADH from the assay resulted in about a $15 \%$ decline in reducing activity, the substitution of NADPH could not restore activity. Finally, a complete $\mathrm{Fe}^{3+}$ reduction assay was performed with other iron sources substituted for ferric 
Table 2. Reduction of iron sources by $L$. monocytogenes 35152

Bacteria were grown at $25^{\circ} \mathrm{C}$ without aeration for $18 \mathrm{~h}$ prior to being used in a ferric reduction assay. Values are means \pm SD of at least three separate assays.

\begin{tabular}{|lc|}
\hline Source of ferric iron & $\begin{array}{c}\text { Specific activity } \\
\left(\boldsymbol{\mu} \mathbf{m o l} \mathbf{F e}^{2+}-\text { ferrozine }\right. \\
\mathbf{m i n}^{-1} \mathbf{O D U}^{-1} \text { ) }\end{array}$ \\
\hline Ferric ammonium citrate & $4 \cdot 02 \pm 0 \cdot 27$ \\
Ferric chloride & $2 \cdot 01 \pm 0.59$ \\
Ferric pyrophosphate & $1 \cdot 55 \pm 0.33$ \\
Ferritin, holo & $2 \cdot 20 \pm 0 \cdot 25$ \\
Lactoferrin, 50\% iron-loaded & $0 \cdot 18 \pm 0.02$ \\
Transferrin, 50\% iron-loaded & $0 \cdot 23 \pm 0.07$ \\
Haemoglobin & $0 \cdot 43 \pm 0 \cdot 12$ \\
Ferric-Desferal & $1 \cdot 58 \pm 0.35$ \\
Ferric-dihydroxybenzoic acid & $2 \cdot 75 \pm 0 \cdot 25$ \\
\hline
\end{tabular}

Table 3. $\mathrm{Fe}^{3+}$ reduction after separation of bacteria and iron source

The experimental conditions were as described in Methods. Bacteria and ferritin were separated by a $25000 \mathrm{Da}$ cutoff dialysis membrane. After a $45 \mathrm{~min}$ incubation, the amount of $\mathrm{Fe}^{2+}$-ferrozine formed on the 'bacteria' side of the membrane and on the 'ferritin' side of the membrane was determined spectrophotometrically. The results shown are typical of three separate experiments.

\begin{tabular}{|lc|}
\hline Experimental condition & $\begin{array}{c}\mathbf{F e}^{2+} \text {-ferrozine } \\
\text { formed ( } \boldsymbol{\mu m o l})\end{array}$ \\
\hline Dialysis membrane - bacteria side & 1.36 \\
Dialysis membrane - ferritin side & 0.68 \\
No dialysis membrane* & 26.9 \\
\hline
\end{tabular}

*Indicates that the bacteria and ferritin were not separated by a dialysis membrane but were in direct contact with each other.

ammonium citrate. Release of $\mathrm{Fe}^{2+}$ was seen in all cases, although to varying degrees (Table 2).

\section{Requirement for contact between bacteria and iron sources}

The failure to detect significant $\mathrm{Fe}^{3+}$-reducing activity in the cell-free culture supernatants from $L$. monocytogenes suggested that direct contact between the bacteria and the iron source may be necessary for $\mathrm{Fe}^{3+}$ reduction. An assay was designed in which bacteria were separated from a source of ferric iron (ferritin) by a $25000 \mathrm{Da}$ cutoff dialysis membrane, while ferrozine and other components of the standard reduction assay were present on both sides of the membrane. The results, shown in Table 3, indicate that reduction of $\mathrm{Fe}^{3+}$ from ferritin only occurred when the bacteria and ferritin were in direct contact.

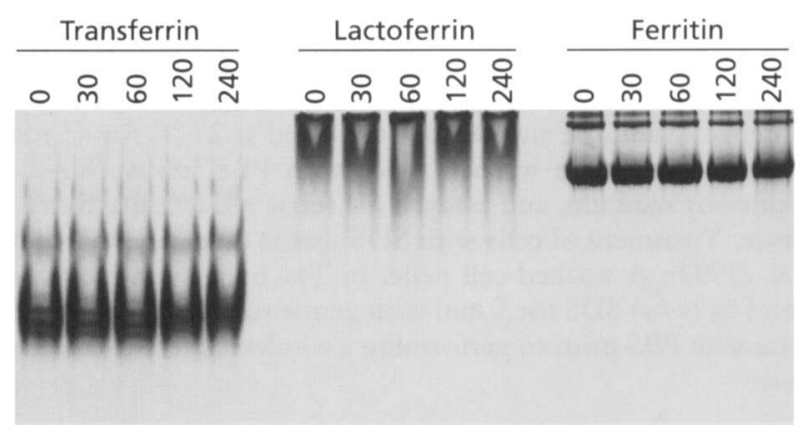

Fig. 2. Non-denaturing PAGE of iron-containing proteins. Transferrin, lactoferrin or ferritin were each exposed to $L$. monocytogenes 35152 as described in Methods. At the indicated time points $(0-240 \mathrm{~min})$ the bacteria were removed and an aliquot of the supernatant containing $20 \mu \mathrm{g}$ of the ironprotein was electrophoresed on an $8 \%$ native polyacrylamide gel and stained with Coomassie Brilliant Blue R-250.

To determine whether iron reduction was sensitive to the proteolysis of bacterial cell wall components, whole cells of $L$. monocytogenes were treated with proteolytic agents prior to performing an $\mathrm{Fe}^{3+}$ reduction assay. The specific activities for $\mathrm{Fe}^{3+}$ reduction in treated cells, expressed as a percentage of that seen in non-treated control bacteria, were as follows: proteinase $\mathrm{K}$ treatment, $116 \%$; trypsin treatment, $113 \%$; SDS treatment, $7 \%$.

Finally, we considered the possibility that release of $\mathrm{Fe}^{2+}$ from the protein-iron chelates might require that the proteins be degraded prior to iron reduction. To test this, transferrin, lactoferrin and ferritin were incubated with whole Listeria cells and then monitored for proteolysis by non-denaturing PAGE. Even after $4 \mathrm{~h}$ of incubation, no degradation of the iron proteins could be seen (Fig. 2).

\section{Release of ferrous iron during $\mathrm{Fe}^{3+}$ reduction}

Since it appeared that exogenous ferric iron was being reduced at the bacterial cell surface, we thought it possible that free ferrous iron could be released into the assay medium. To test this, a whole-cell suspension of $L$. monocytogenes was incubated for 25 min with ferric ammonium citrate, $\mathrm{NADH}, \mathrm{FMN}$ and $\mathrm{MgCl}_{2}$, but without ferrozine. After this time, the cells were removed by centrifugation and ferrozine was added to the supernatant and allowed to incubate for $1 \mathrm{~min}$. By assaying the supernatant spectrophotometrically, we found that only $4.5 \mu \mathrm{mol} \mathrm{Fe}^{2+}$-ferrozine had formed. Allowing the ferrozine-containing supernatant to incubate for longer times did not significantly change this value, indicating that all the available $\mathrm{Fe}^{2+}$ had complexed with ferrozine. In contrast, a control cell suspension in which ferrozine was present with bacteria throughout the $25 \mathrm{~min}$ incubation formed $35 \cdot 1 \mu \mathrm{mol} \mathrm{Fe}{ }^{2+}$-ferrozine.

\section{Effect of growth conditions on $\mathrm{Fe}^{3+}$ reduction}

Very little difference was noted in the $\mathrm{Fe}^{3+}$-reducing ability of $L$. monocytogenes 35152 harvested at various stages of growth (Table 4). Similarly, bacteria grown in 
Table 4. Effect of growth conditions on $\mathrm{Fe}^{3+}$ reduction by $L$. monocytogenes 35152

In all cases bacteria were grown at $37^{\circ} \mathrm{C}$ prior to assay. Ferric ammonium citrate was the iron source in all assays. Values are means \pm SD from triplicate experiments, except for the growth phase experiment which shows data from a typical experiment, repeated three times.

\begin{tabular}{|lc|}
\hline Growth condition & $\begin{array}{c}\text { Specific activity } \\
(\boldsymbol{\mu} \text { mol Fe } \\
\left.\text { min }^{-1} \text { ODU }^{-1}\right)\end{array}$ \\
\hline Early exponential phase & 3.56 \\
$\left(\mathrm{OD}_{600}=0 \cdot 236\right)$ & \\
Late exponential phase & 3.54 \\
$\left(\mathrm{OD}_{600}=0 \cdot 622\right)$ & \\
Stationary phase $\left(\mathrm{OD}_{600}=1.315\right)$ & 3.29 \\
Low-iron medium & $3.57 \pm 0.28$ \\
Low-iron medium $+\mathrm{FeCl}_{3}$ & $3.69 \pm 0.43$ \\
pH 7.20 medium & $3.49 \pm 0.19$ \\
pH 5.45 medium & $1.82 \pm 0.05$ \\
Aerobic (aeration) & $3.50 \pm 0.24$ \\
Aerobic (static) & $2.34 \pm 0.37$ \\
Anaerobic & $0.61 \pm 0.08$ \\
\hline
\end{tabular}

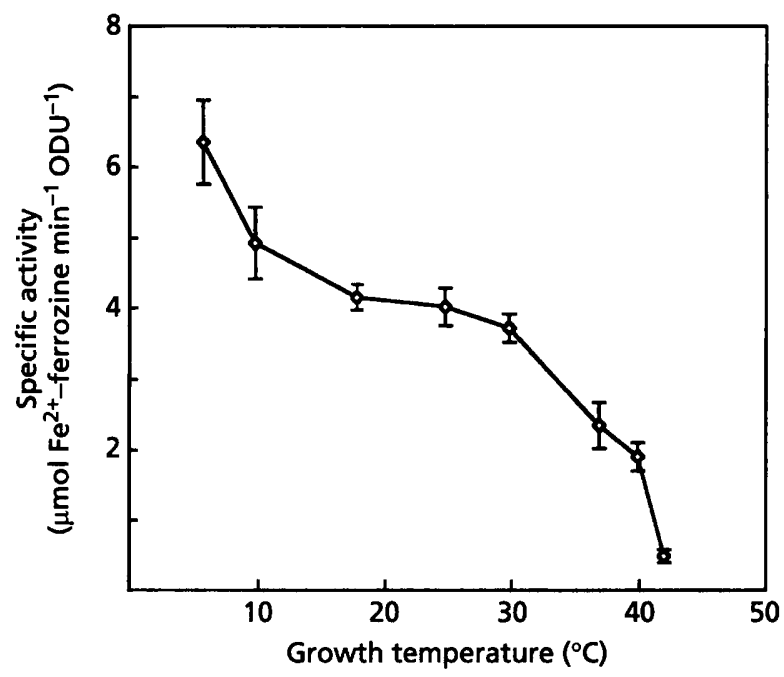

Fig. 3. Ferric reductase activity of $L$. monocytogenes ATCC 35152 as a function of growth temperature. Individual bacterial cultures were grown to early stationary phase at each of the temperatures indicated. Cells from each temperature point were then assayed for ferric reductase activity at $37^{\circ} \mathrm{C}$ using the standard whole-cell assay described in Methods. Each data point represents the mean $\pm S D$ of three to five separate experiments at each temperature.

iron-reduced and iron-supplemented media had equivalent $\mathrm{Fe}^{3+}$-reducing activities. However, L. monocytogenes grown without aeration or anaerobically showed considerably less $\mathrm{Fe}^{3+}$-reducing activity than cells grown under highly aerobic conditions (Table 4). Also, bacteria
Table 5. $\mathrm{Fe}^{3+}$ reduction by Listeria and other species of bacteria

Values shown are the means $\underline{\mathrm{SD}}$ of triplicate experiments.

\begin{tabular}{|c|c|c|}
\hline Species & Serotype & $\begin{array}{c}\text { Specific activity } \\
\left(\mu \mathrm{mol} \mathrm{Fe}^{2+}-\right. \\
\text { ferrozine } \min ^{-1} \\
\left.\text { ODU }{ }^{-1}\right)\end{array}$ \\
\hline \multicolumn{3}{|l|}{ L. monocytogenes } \\
\hline ATCC 35152 & $1 / 2 a$ & $4 \cdot 02 \pm 0 \cdot 20$ \\
\hline ATCC 43256 & - & $15 \cdot 20 \pm 0 \cdot 90$ \\
\hline ATCC 15313 & - & $16 \cdot 10 \pm 2 \cdot 30$ \\
\hline ATCC 19113 & 3 & $2 \cdot 08 \pm 0 \cdot 18$ \\
\hline SB & $1 / 2 b$ & $14 \cdot 50 \pm 1 \cdot 80$ \\
\hline D-20 & $4 b$ & $12 \cdot 90 \pm 2 \cdot 70$ \\
\hline 058 & $1 / 2 b$ & $14 \cdot 40 \pm 1 \cdot 50$ \\
\hline 615776 & - & $14 \cdot 10 \pm 2 \cdot 40$ \\
\hline 223556 & - & $17 \cdot 30 \pm 0 \cdot 76$ \\
\hline Listeria ivanovii & - & $27 \cdot 20 \pm 1 \cdot 10$ \\
\hline Listeria seeligeri & - & $23 \cdot 90 \pm 0 \cdot 35$ \\
\hline Listeria grayi & - & $27 \cdot 90 \pm 3 \cdot 30$ \\
\hline Listeria welsbimeri & - & $11 \cdot 20 \pm 1.90$ \\
\hline Listeria innocua & - & $26 \cdot 00 \pm 1 \cdot 70$ \\
\hline Listeria murrayi & - & $9 \cdot 80 \pm 2 \cdot 10$ \\
\hline Eschericbia coli 0157 & - & $0 \cdot 52 \pm 0 \cdot 14$ \\
\hline Enterococcus faecalis & - & $0 \cdot 89 \pm 0 \cdot 10$ \\
\hline
\end{tabular}

grown in media of reduced $\mathrm{pH}$ showed a decreased ability to reduce ferric iron (Table 4).

Because Listeria are psychrotrophic in nature (Farber \& Peterkin, 1991), we examined the effect of growth temperature on $\mathrm{Fe}^{3+}$-reducing activity. Cultures of $L$. monocytogenes 35152 were grown at temperatures ranging from 6 to $42{ }^{\circ} \mathrm{C}$, harvested and assayed at $37^{\circ} \mathrm{C}$ for their ability to reduce ferric citrate. As shown in Fig. 3, coldcultured bacteria showed a two-threefold higher rate of $\mathrm{Fe}^{3+}$ reduction than did bacteria grown at $37^{\circ} \mathrm{C}$, and a $12-14$-fold higher rate than bacteria grown at $42^{\circ} \mathrm{C}$.

\section{$\mathrm{Fe}^{3+}$ reduction by other species of Listeria}

While our initial studies on ferric iron reduction were done with a virulent strain of $L$. monocytogenes (ATCC 35152), we also examined other strains and other species of Listeria for comparative purposes. Identical growth conditions were used in all cases so that any differences in $\mathrm{Fe}^{3+}$-reducing activity could be attributed to the strains themselves. All reference and clinical isolates of $L$. monocytogenes were able to reduce ferric citrate and most in fact produced three-fourfold higher levels of reducing activity than did L. monocytogenes 35152 (Table 5). Finally, we found that other species of Listeria could also reduce extracellular iron and in several cases were more efficient at $\mathrm{Fe}^{3+}$ reduction than was $L$. monocytogenes (Table 5). By comparison, E. coli and Ent. faecalis had minimal $\mathrm{Fe}^{3+}$ reducing activity in the whole-cell assay (Table 5) and 
similar results have been found with a range of other Gram-negative and Gram-positive bacteria (not shown).

\section{DISCUSSION}

Although iron is an essential nutrient for L. monocytogenes, the mechanisms of iron acquisition have remained largely uncharacterized and, given the diversity of habitats occupied by this micro-organism, might be expected to be relatively complex. Whilst Listeria does not produce siderophores, it has been reported to secrete an ironreducing compound of $8000-10000 \mathrm{Da}$ able to release $\mathrm{Fe}^{2+}$ from transferrin (Cowart \& Foster, 1985) and is apparently able to bind the iron chelate ferric citrate to the cell surface (Adams et al., 1990). In this report, we show that intact cell suspensions of $L$. monocytogenes, when exposed to ferric iron, rapidly produce ferrous iron which can be detected as chromogenic $\mathrm{Fe}^{2+}$-ferrozine complexes in the supernatant. Because ferrozine is a sulfonated compound and should not readily traverse the cell membrane (Stookey, 1970; Evans et al., 1986), we believe that we are observing only the reduction of external ferric iron by Listeria.

Several lines of evidence suggest that ferric iron reduction by $L$. monocytogenes, as described here, is a novel activity and not related to the low molecular mass secreted 'reductant' reported by Cowart \& Foster (1985). Firstly, ferric ammonium citrate was not reduced when incubated with the spent cell-free culture supernatant in which Listeria had been grown. However, it is not known whether the secreted 'reductant' is able to reduce iron bound in forms other than ferric transferrin, since in the original report by Cowart \& Foster (1985), only transferrin was tested. Secondly, cells which had been extensively washed prior to being exposed to ferric iron were nevertheless able to immediately form ferrozinechelatable $\mathrm{Fe}^{2+}$. Finally, and most convincingly, iron was not reduced if it was separated from bacteria by a membrane which did allow low molecular mass $(<25000 \mathrm{Da})$ compounds, such as a 'reductant', to pass through. These results suggest that a direct physical interaction between iron and the bacterial cell surface is required before reduction occurs. It is noteworthy that this interaction was not sensitive to proteolysis by trypsin or proteinase $\mathrm{K}$. In fact, a slight increase in ferric reduction activity was seen after treatment with proteolytic enzymes. Possibly, the surface components required for iron reduction are buried within the cell wall and are made more accessible by the action of proteolytic agents. A similar phenomenon has been observed with the surface iron-binding receptors of Legionella pneumophila (Johnson et al., 1991). Nevertheless, treatment of bacteria with SDS, which is known to remove surface proteins from Listeria but not to lyse the cells, resulted in the elimination of most of the iron-reducing activity. This suggests that more extensive disruption of surface integrity, as would occur with SDS, is required before iron-reducing activity is lost.

Two general classes of enzymes which function as ferric iron reductases are recognized in bacteria: one type is plasma-membrane-bound and linked to the respiratory electron transport chain (Lascelles \& Burke, 1976; Dailey \& Lascelles, 1977), while the other type is cytoplasmic or periplasmic and functions mainly as a ferrisiderophore reductase, releasing $\mathrm{Fe}^{2+}$ from internalized $\mathrm{Fe}^{3+}$ siderophore complexes (Arceneaux, 1983; Lesuisse et al., 1987; Johnson et al., 1991). This latter group of enzymes often requires reduced nicotinamides and flavins as cofactors. It is unclear whether the activity we have observed in L. monocytogenes is related to either of these classes of enzymes. We found that reduction of ferric iron was slightly stimulated by the addition of NADH, but not NADPH, to the cell suspension and could be further enhanced by the addition of FMN and magnesium ions. Although these results suggest a cofactor requirement of some kind, our assays were performed with intact, metabolically active cells and a detailed characterization of the reductase activity must await its purification.

It is evident, however, that the iron reductase activity of L. monocytogenes is directed toward external iron and as such may be more analogous to the plasma membrane ferric reductase of Saccharomyces cerevisiae which is also able to reduce a variety of extracellular iron chelates (Moody \& Dailey, 1984; Dancis et al., 1990; Lesuisse et al., 1991). Similarly, it has been proposed that Streptococcus mutans possesses an as yet uncharacterized membrane flavin reductase able to reduce and solubilize ferric iron polymers bound to the cell surface (Evans et al., 1986). Our data suggests that while iron reduction is occurring at the Listeria cell surface, the $\mathrm{Fe}^{2+}$ which is formed is not released into the medium surrounding the cells but presumably is immediately bound by a cell surface receptor. If ferrozine is present in a cell suspension while iron reduction is occurring, as is the case in our whole-cell reduction assay, then a $\mathrm{Fe}^{2+}$-ferrozine complex may form before the solubilized $\mathrm{Fe}^{2+}$ is able to interact with its cellular receptor. Based on this, we propose that iron acquisition by Listeria is a multi-step process similar to that thought to occur in Strep. mutans (Evans et al., 1986). Iron as ferric chelates would be bound to the bacterial surface via specific or non-specific receptors and would then be reduced to the $\mathrm{Fe}^{2+}$ form by the surface-associated ferric reductase. The reduced iron would then become bound to, and transported by, a specific surface-localized $\mathrm{Fe}^{2+}$ receptor. This model differs from that of Adams $e t a l$. (1990) only in that iron reduction would largely be achieved by a surface-bound activity rather than by a secreted soluble reductant. An important consideration in this model is the precise nature of the $\mathrm{Fe}^{2+}$ receptor, how it binds and transports ferrous iron, and whether it must interact in some way with the ferric reductase activity. Clearly, an examination of the fate of the reduced iron, once formed, is necessary to address these questions.

In addition, the role in iron acquisition of the previously described secreted 'reductant' must be addressed. It is possible that the soluble reductant has a specialized function in removing iron from transferrin in vivo, whereas the cell-bound reducing activity is more generalized and gives $L$. monocytogenes the opportunity to use a range of iron chelates found in different environments. In support of this is our finding that many types of ferric iron, 
including iron salts found in natural environments, biological chelates of iron which would be encountered by the bacteria in vivo, and iron in the form of $\mathrm{Fe}^{3+}$ siderophore complexes such as Desferal and dihydroxybenzoic acid, were reduced by $L$. monocytogenes. This suggests that in bacterial consortiums in nature for example, Listeria may not require their own siderophores because they can use those produced by other species. In addition, reduction and release of iron was observed, albeit slowly, from lactoferrin, transferrin and haemoglobin, whereas the release of $\mathrm{Fe}^{2+}$ from ferritin proceeded relatively rapidly. Since ferritin is a major storage form of iron in phagocytic cells (Kemp, 1993), it is possible that intracellular Listeria are able to access these stores and liberate ferrous iron for growth. Exactly how iron reduction from ferritin or other protein carriers is achieved is not known, although our data indicate that the proteolytic cleavage of these proteins by a cellular protease is not involved. In contrast, the pyoverdin-mediated uptake of iron from transferrin by Pseudomonas aeruginosa appears to require the cleavage of the iron-carrying glycoprotein by a cellular elastase (Doring et al., 1988).

In keeping with the proposed role of the cell-bound reductase as a component of a general iron scavenging system, we found that all species of Listeria were highly efficient at reducing iron. In fact, many non-pathogenic Listeria which have a widespread environmental distribution, had higher ferric reductase specific activities than did the pathogenic $L$. monocytogenes. It is probable that Listeria species have evolved a common iron uptake mechanism, based on iron reduction, which is flexible enough to be used in the many different environmental situations which the bacteria may encounter.

The final aspect of this work, and potentially one of relevance to the pathogenicity of Listeria, concerns the regulation of the ferric reductase activity. We found that the iron-reducing activity of $L$. monocytogenes was not affected by the growth phase of the bacteria nor by the iron status of the cells. This is in contrast to the reported stimulation of ferric reductase activity by iron-restriction in Sacch. cerevisiae (Dancis et al., 1990). On the other hand, ferric iron reduction declined by more than $80 \%$ when Listeria were grown anaerobically compared to being vigorously aerated. Similarly, growth of Listeria in mildly acidic media resulted in a significant decline in ferric reductase activity. Being a facultative anaerobe, Listeria is able to live in oxygen-depleted environments where ferrous iron may be readily available. Also, the acidic, anaerobic environment of the gut, which serves as a portal of entry for food-borne Listeria, might be expected to contain mostly ferrous iron. In environments such as these, Listeria would presumably no longer require an enzymic activity directed at reducing external iron and might therefore repress such an activity.

More unusual was our finding that ferric reductase activity was highest in Listeria which had been cultured at refrigeration temperatures and decreased as the growth temperature increased. The significance of this observation, and whether it has implications for the virulence of L. monocytogenes, is unclear. Unlike other bacteria where cold-inducible gene expression has been well documented (Jones \& Inouye, 1994), the effect of cold temperature growth on the physiology of Listeria is poorly understood. It has recently been observed that the active transport of glycine betaine by $L$. monocytogenes can be stimulated up to 15-fold by growth of the bacteria at cold temperatures (Ko et al., 1994). This is comparable to the stimulation of ferric reductase activity we observed when Listeria grown at 6 and $42{ }^{\circ} \mathrm{C}$ were compared. It has also been shown that $L$. monocytogenes grown at low temperatures are more virulent in the intravenous mouse model than are bacteria grown at $37^{\circ} \mathrm{C}$ (Czuprynski et al., 1989; Stephens et al., 1991), although the reasons for this are unclear. It is possible that prolonged storage of Listeria at refrigeration temperatures will lead to increased ferric reductase activity and thereby contribute to increased virulence. Experiments aimed at clarifying the relationship between iron-reducing ability and virulence in Listeria are in progress.

\section{ACKNOWLEDGEMENTS}

This work was supported by a grant from the Medical Research Council of Canada to H.G.D.

\section{REFERENCES}

Adams, T. S., Vartivarian, S. \& Cowart, R. E. (1990). Iron acquisition systems of Listeria monocytogenes. Infect Immun 58, 2715-2718.

Arceneaux, J. E. L. (1983). Ferrisiderophore reductases and iron assimilation. In Microbiology-1983, pp. 288-292. Edited by D. Schlessinger. Washington, DC: American Society for Microbiology.

Cowart, R. E. \& Foster, B. (1985). Differential effects of iron on the growth of Listeria monocytogenes: minimum requirements and mechanism of acquisition. J Infect Dis 151, 721-730.

Cowart, R. E., Fillmore, K., Kardatzke, J. \& Barchini, E. (1988). Abstract D-179. In Abstracts of the Annual Meeting of the American Society for Microbiology 1988, p. 101.

Crichton, R. R. \& Ward, R. (1992). Iron metabolism - new perspectives in view. Biochemistry 31, 11255-11264.

Czuprynski, C., Brown, J. F. \& Roll, J. T. (1989). Growth at reduced temperatures increases the virulence of Listeria monocytogenes for intravenously but not intragastrically inoculated mice. Microb Pathogen 7, 213-223.

Dailey, H. \& Lascelles, J. (1977). Reduction of iron and synthesis of protoheme by Spirillum itersonii and other organisms. J Bacteriol 129, 815-820.

Dancis, A., Klausner, R., Hinnebusch, A. \& Barriocanal, J. (1990). Genetic evidence that ferric reductase is required for iron uptake in Saccbaromyces cerevisiae. Mol Cell Biol 10, 2294-2301.

Deneer, H. G. \& Boychuk, I. (1993). Reduction of ferric iron by Listeria monocytogenes and other species of Listeria. Can J Microbiol 39, 480-485.

Doring, G., Pfestorf, M., Botzenhart, K. \& Abdallah, M. (1988). Impact of proteases on iron uptake of Pseudomonas aeruginosa pyoverdin from transferrin and lactoferrin. Infect Immun 56, 291-293.

Evans, S. L., Arceneaux, J., Byers, B., Martin, M. \& Aranha, H. (1986). Ferrous iron transport in Streptococcus mutans. J Bacteriol 168, 1096-1099. 
Farber, J. M. \& Peterkin, P. I. (1991). Listeria monocytogenes: a food-borne pathogen. Microbiol Rev 55, 476-511.

Gaines, C. G., Lodge, J., Arceneaux, J. \& Byers, B. (1981). Ferrisiderophore reductase activity associated with an aromatic biosynthetic enzyme complex in Bacillus subtilis. J Bacteriol 148, 527-533.

Gutteridge, J. M. C. (1987). A method for removal of trace iron contamination from biological buffers. FEBS Lett 214, 362-364.

Johnson, W., Varner, L. \& Poch, M. (1991). Acquisition of iron by Legionella pneumophila: role of iron reductase. Infect Immun 59, 2376-2381.

Jones, P. \& Inouye, M. (1994). The cold-shock response - a hot topic. Mol Microbiol 11, 811-818.

Kemp, J. D. (1993). The role of iron and iron binding proteins in lymphocyte physiology and pathology. J Clin Immunol 13, 81-92.

Kluge, R. M. (1990). Listeriosis-problems and therapeutic options. J Antimicrob Chemother 25, 887-890.

Ko, R., Smith, L T. \& Smith, G. M. (1994). Glycine betaine confers enhanced osmotolerance and cryotolerance on Listeria monocytogenes. $J$ Bacteriol 176, 426-431.

Kocks, C., Gouin, E., Tabourat, M., Berche, P., Ohayon, H. \& Cossart, P. (1992). Listeria monocytogenes-induced actin assembly requires the act $A$ gene product, a surface protein. Cell 68, 521-531.

Lascelles, J. \& Burke, K. (1976). Reduction of ferric iron by L-lactate and DL-glycerol 3-phosphate in membrane preparations from Staphylococcus aureus and interactions with the nitrate reductase system. $J$ Bacteriol 134, 585-589.

Lesuisse, E., Raguzzi, F. \& Crichton, R. (1987). Iron uptake by the yeast Saccharomyces cerevisiae: involvement of a reduction step. $J$ Gen Microbiol 133, 3229-3236.

Lesuisse, E., Horion, B., Labbe, P. \& Hilger, F. (1991). The plasma membrane ferrireductase activity of Saccharomyces cerevisiae is partially controlled by cyclic AMP. Biochem J 280, 545-548.

Moody, M. \& Dailey, H. (1984). Siderophore utilization and iron uptake by Rhodopseudomonas sphaeroides. Arch Biochem Biophys 234, 178-186.

Neilands, J. B. (1981). Microbial iron compounds. Annu Rev Biochem 50, 715-731.

Portnoy, D. A., Chakraborti, T., Goebel, W. \& Cossart, P. (1992). Molecular determinants of Listeria monocytogenes pathogenesis. Infect Immun 60, 1263-1267.

Simonson, C., Brener, D. \& DeVoe, I. (1982). Expression of a highaffinity mechanism for acquisition of transferrin iron by Neisseria meningitidis. Infect Immun 36, 107-113.

Stephens, J. C., Roberts, I. S., Jones, D. \& Andrew, P. W. (1991). Effect of growth temperature on virulence of strains of Listeria monocytogenes in the mouse: evidence for growth dependence. $J A p p l$ Bacteriol 70, 239-244.

Stookey, L. L. (1970). Ferrozine: a new spectrophotometric reagent for iron. Anal Chem 42, 779-781.

Sword, C. P. (1966). Mechanisms of pathogenesis in Listeria monocytogenes infections. I. Influences of iron. J Bacteriol $92,536-542$.

Vasconcelos, J. \& Deneer, H. G. (1994). Expression of superoxide dismutase in Listeria monocytogenes. Appl Environ Microbiol 60, 2360-2366.

Yang, H., Kool, C. \& Sokol, P. A. (1993). Ability of Pseudomonas pseudomallei malleobactin to acquire transferrin-bound iron, lactoferrin-bound iron, and cell-derived iron. Infect Immun 61, 656-662.

Received 5 December 1994; revised 24 March 1995; accepted 20 April 1995. 